\title{
FAST INFRARED IMAGING TO STUDY BURNER FLUCTUATIONS
}

\author{
${ }^{1}$ Istituto di Ricerca sulla Combustione CNR, Italy \\ allouis@irc.cnr.it
}

C. Allouis ${ }^{1 *}$, F. Beretta ${ }^{1}$

The environmental aspect becomes always more important for the development of energetic and propulsive technology; the future regulations will require a better control on the nitrogen oxides, particulate and inorganic compounds emitted from combustion sources. Atomization and vaporization processes notably influence the formation of the pollutants in the combustion chamber and consequently their emissions.

Researches were focused on new concepts for ultra-low emissions combustors, with developments in fuel preparation and wall cooling techniques. A possible technological solution for the reduction of pollution is the use of lean mixtures premixed and prevaporized before they enter combustion chamber. These new emergent technologies are affected by many problems that must be resolved in order to make it in reliable for commercial engines.

Numerous experimental studies and numerical models were developed to understand the behaviour of gas turbines with Lean Premixed Prevaporized technology; in particular there are current researches to understand fuel/air interaction in the premixing duct, upstream of the combustion chamber. Moreover, the fluctuations of such systems may cause several problem of stability of the engines. Many work were performed to characterize these fluctuations using different laser based techniques. The idea was to use the IR emission of the flame as a tracer of the fluctuations. The recent availability of new fast InfraRed camera is a good opportunity to obtain information in "quasi" real time. The availability of the broad band IR sensor 1.5-5 micron of the camera was a good solution for our investigations. In this paper are presented preliminary results obtained in different burner types. A picture of a typical flame of LPP burner is presented in figure 1. an example of FFT analysis of IR images is presented in figure 2.

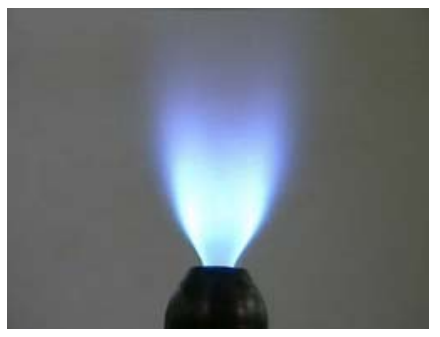

Figure 1. Typical picture of a lean flame (AFR=25, frame rate $50 \mathrm{f} / \mathrm{s}$ ).

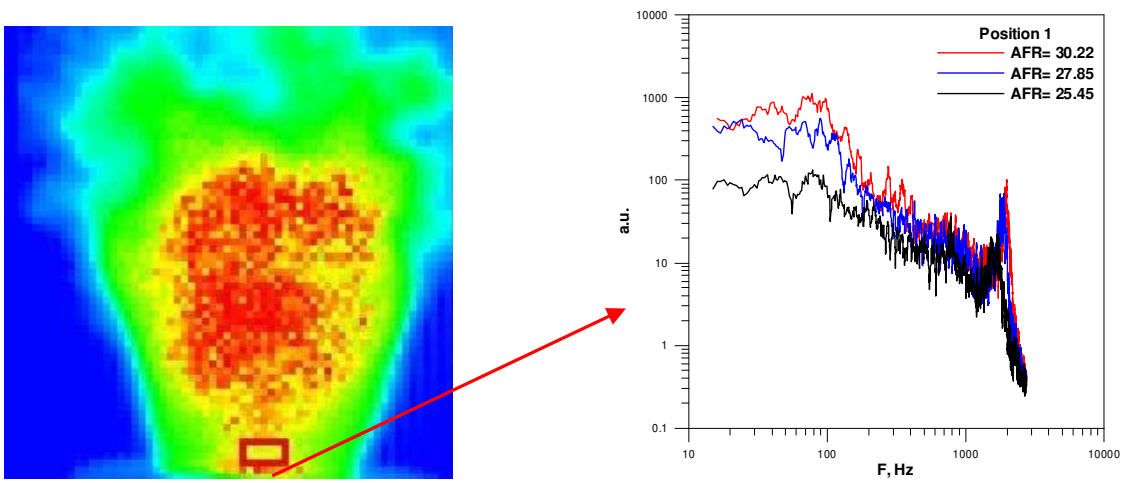

Figure 2. Frequency analysis of IR images at the center. 
http://dx.doi.org/10.21611/qirt.2008.06_01_08 